Article

\title{
Dual Transcriptomic Analysis Reveals a Delayed Antiviral Response of Haliotis diversicolor supertexta against Haliotid Herpesvirus-1
}

\author{
Chang-Ming Bai 1,2 (D), Shu-Min Zhang ${ }^{1,3}$, Ya-Na Li ${ }^{1,4}$, Lu-Sheng Xin 1,2 ${ }^{\mathbb{D}}$, \\ Umberto Rosani ${ }^{5,6, *(D)}$ and Chong-Ming Wang ${ }^{1,2, *}$
}

1 Key Laboratory of Maricultural Organism Disease Control, Ministry of Agriculture, Qingdao Key Laboratory of Mariculture Epidemiology and Biosecurity, Yellow Sea Fisheries Research Institute, Chinese Academy of Fishery Sciences, Qingdao 266071, China; baicm@ysfri.ac.cn (C.-M.B.); zhangshumin1223@foxmail.com (S.-M.Z.); lyn19933@163.com (Y.-N.L.); xinls@ysfri.ac.cn (L.-S.X.)

2 Laboratory for Marine Fisheries Science and Food Production Processes, Qingdao National Laboratory for Marine Science and Technology, Qingdao 266237, China

3 Department of Fisheries and Life Science, Dalian Ocean University, Dalian 116023, China

4 Department of Fisheries, Tianjin Agriculture University, Tianjin 300380, China

5 Department of Biology, University of Padua, 35121 Padua, Italy

6 Alfred Wegener Institute (AWI) - Helmholtz Centre for Polar and Marine Research, Wadden Sea Station Sylt, 25992 List, Germany

* Correspondence: umberto.rosani@unipd.it (U.R.); wangcm@ysfri.ac.cn (C.-M.W.); Tel.: +39-049-8276284 (U.R.); +86-532-85823062 (ext. 812) (C.-M.W.)

Received: 25 February 2019; Accepted: 23 April 2019; Published: 24 April 2019

check for updates

\begin{abstract}
Haliotid herpesvirus-1 (HaHV-1) is the first identified gastropod herpesvirus, causing a highly lethal neurologic disease of abalone species. The genome of HaHV-1 has been sequenced, but the functions of the putative genes and their roles during infection are still poorly understood. In the present study, transcriptomic profiles of Haliotis diversicolor supertexta at 0,24 and $60 \mathrm{~h}$ post injection (hpi) with HaHV-1 were characterized through high-throughput RNA sequencing. A total of $448 \mathrm{M}$ raw reads were obtained and assembled into $2.08 \times 10^{5}$ unigenes with a mean length of $1486 \mathrm{bp}$ and an N50 of $2455 \mathrm{bp}$. Although we detected increased HaHV-1 DNA loads and active viral expression at $24 \mathrm{hpi}$, this evidence was not linked to significant changes of host transcriptomic profiles between 0 and $24 \mathrm{hpi}$, whereas a rich immune-related gene set was over-expressed at $60 \mathrm{hpi}$. These results indicate that, at least at the beginning of HaHV-1 infection, the virus can replicate with no activation of the host immune response. We propose that HaHV-1 may evolve more effective strategies to modulate the host immune response and hide during replication, so that it could evade the immune surveillance at the early stage of infection.
\end{abstract}

Keywords: abalone; transcriptome; immune-related genes; apoptosis; HaHV-1

\section{Introduction}

Haliotid herpesvirus-1 (HaHV-1), one of the most devastating viral pathogens of wild and cultivated abalones, is the first identified herpesvirus that infects gastropods [1,2]. HaHV-1 infection was first reported in 2003 in Taiwan, where mass mortalities of cultivated Haliotis diversicolor supertexta were reported [1]. Subsequently, a similar disease was described in the blacklip abalone (Haliotis rubra) and in the greenlip abalone (Haliotis laevigata) in Australia in 2005 [3]. Two recent studies back-dated the appearance of HaHV-1 infection to 1999 in $H$. diversicolor supertexta populations cultivated in Southern China [4,5]. Histological lesions of HaHV-1 infection were characterized by necrotizing 
ganglioneuritis and, therefore, this disease was named Abalone Viral Ganglioneuritis (AVG). Although the complete genome of HaHV-1 has been sequenced, most of its putative proteins still have unknown functions [2]. Phylogenetic analysis based on two conserved proteins, the DNA packaging ATPase subunit of a (putative) terminase and the DNA polymerase, showed that HaHV-1 is closely related to Ostreid herpesvirus-1 (OsHV-1), the first herpesvirus discovered to infect mollusks [6,7], whereas HaHV-1 is only distantly related to the other herpesviruses [2]. This great divergence has prevented the possibility to infer gene functions by homology-based prediction methods [7], greatly limiting the knowledge on these two herpesviruses.

Herpesviruses are large dsDNA viruses, often evolved with their host over a long period of time resulting in a strict host-virus co-adaptation [8]. Vertebrate herpesviruses used many strategies to circumvent the host immune responses or delay them [9-12]. The infection mechanisms and the viral and host key genes involved during the infection process have been characterized for a number of vertebrate herpesviruses, and they were used to develop preventative or therapeutic measures $[9,13]$. Conversely, the antiviral responses of mollusks need further work to be extensively understood [14-18]. The lack of continuous molluscan cell lines supporting viral growth and replication in vitro greatly hampered the application of the classical virology approaches to these viruses [14]. Molecular approaches and the introduction of next-generation sequencing (NGS) techniques have increased the possibility to understand viral genomic diversity and transcriptional landscape of OsHV-1 [19-23]. Dual transcriptomic analysis of the cross-talk between OsHV-1 and bivalve mollusks active infection processes have been also carried out [16,24-27]. These studies revealed a rich set of genes and pathways in bivalves, especially in Crassostrea gigas, involved in the immune defense against OsHV-1 infection [14,16,28-30]. One of the highly noticeable pathways revealed by these studies is apoptosis [16,18,25], which also plays an important role in eliminating herpesvirus-infected cells in vertebrates [31-33]. To evade elimination by apoptosis and guarantee viral propagation, herpesviruses have evolved various strategies to suppress host cell apoptosis. OsHV-1 genome encodes several putative inhibitors of apoptosis (IAPs) capable of suppressing host apoptosis and allowing its own replication $[7,28]$. Moreover, some key anti-apoptotic factors regulating apoptotic signaling pathway were also over-expressed during OsHV-1 infection $[16,25,26,28]$. The apoptosis signaling pathway is certainly not isolated, many other key components associated with antiviral responses, including interferon pathways, toll-like pathways, and oxidative bursts have been reported in C. gigas $[14,16,25]$. Another remarkable observation during the interaction between C. gigas and OsHV-1 was that the early antiviral response (before $24 \mathrm{~h}$ after infection) was important to successfully counteract the viral infection [27].

Although it is expected that several other herpesviruses that infect invertebrates exist [2], HaHV-1 and OsHV-1 represent the most destructive viral disease of mollusks worldwide [34]. HaHV-1 was less studied compared to OsHV-1, and no data are available to characterize the molecular mechanisms underlying the viral pathogenesis and abalone's countermeasures. In this study, we characterized the dual transcriptome changes of HaHV-1 and H. diversicolor supertexta at 0,24 , and $60 \mathrm{~h}$ post injection (hpi). We provided an annotated transcriptome of $H$. diversicolor supertexta and the first insight into its antiviral pathways. Our analysis indicated an unexpected delay in the immune response to HaHV-1 infection. Globally, these transcriptomic data provided a valuable resource for the gastropod research community.

\section{Materials and Methods}

In April 2016, approx. $400 \mathrm{H}$. diversicolor supertexta specimens (size range from 49.73 to $58.24 \mathrm{~mm}$, $n=30$ ) were transferred by air from Xiamen to our aquaculture facilities in Qingdao (YSFRI). The abalones were derived from hatchery produced seeds reproduced from 50 pairs of parental abalones. The abalones were cultivated in 50-L tanks (approximately 40 abalones per tank) supplied with aerated, sand-filtered seawater, and fed with seaweed (Laminaria japonica). The water temperature was maintained at approximately $18{ }^{\circ} \mathrm{C}$, and half-changed daily during the acclimation period of two 
weeks. At the end of acclimation, $30 \mathrm{H}$. diversicolor supertexta were selected randomly and tested to be negative for HaHV-1 DNA.

For viral inoculum preparation, the standard protocol used for OsHV-1 and described in [35] was employed except for the use of natural seawater in all dilution steps. A single infected H. diversicolor supertexta (HaHV-1-CN2003) was used as a source of HaHV-1. This specimen was originally collected during abnormal mortality outbreaks in Guangdong Province, China in 2003 [5]. Tissue homogenates for negative controls were prepared using HaHV-1 PCR negative H. diversicolor supertexta animals applying the same protocol. A small aliquot of each homogenate $(200 \mu \mathrm{L})$ was used for HaHV-1 DNA detection and quantification, as described above.

For experimental infection, abalones were "anesthetized" (myo-relaxation) with $10 \mathrm{~g} / \mathrm{L} \mathrm{of} \mathrm{MgCl} 2$ and randomly divided into challenged and negative control groups composed by 180 and 70 individuals, respectively. Once the abalones were relaxed, $100 \mu \mathrm{L}$ of viral inoculums $\left(1.0 \times 10^{4}\right.$ copies of HaHV-1 $\mathrm{DNA} / \mu \mathrm{L}$ ) or control tissue homogenates were injected into the pedal muscle using $1 \mathrm{~mL}$ micro-syringes equipped with 18-g needles. A total of 150 challenged abalones distributed in $50 \mathrm{~L}$ tanks (50 abalones per tank) and 40 control abalones maintained in one $50 \mathrm{~L}$ tank were used for the time course experiment. The remaining 30 individuals per group were maintained in $18 \mathrm{~L}$ tanks (10 abalones per tank) and used for monitoring of mortality rates. Mortality was monitored every $12 \mathrm{~h}$ after infection, and dead abalones were removed from the tank.

At each time point $(0,12,24,30,36,48,60$, and $72 \mathrm{~h}$ post injection, hpi), 6 challenged ( 2 abalones per tank) and 3 control abalones were randomly sampled. The mantle of each abalone was immediately dissected and divided into 2 pieces for DNA and RNA extraction. Dead abalones were collected from each tank and a piece of the mantle was sampled for DNA extraction and HaHV-1 DNA quantification. The DNA extraction was performed using the TIANamp ${ }^{\mathrm{TM}}$ Marine Animals DNA Kit (Tiangen Biotech, Beijing, China), according to the manufacturer's protocol. The purity and quantity of the isolated DNA were determined with a Nanodrop 2000 spectrophotometer (Thermo Fischer Scientific, Waltham, USA). HaHV-1 DNA quantification was carried out by quantitative PCR (qPCR) targeting ORF66 (DNA polymerase) adapted from the World Organization for Animal Health (OIE) Manual of Diagnostic Tests for Aquatic Animals, 2017, and fully described by Bai et al (2019). We estimated the HaHV-1 infection burden of each sample as the mean genomic equivalent (GE) score (ng ${ }^{-1}$ of total DNA).

Mantle tissues of 3 abalones collected at 0, 24, and $60 \mathrm{hpi}$ were selected for RNA-seq according to the measured trend of viral infection burden. The 9 RNA samples were designated as MA00h (1-3), MA24h (1-3), and MA60h (1-3) and sent to Beijing Novogene Technology Co. Ltd. (Beijing, China). for RNA extraction and high-throughput sequencing using the Illumina Hiseq platform (Illumina Inc. San Diego, USA). A total amount of $1.5 \mu \mathrm{g}$ RNA per sample was used as the input material for the library preparations, which were generated using the NEBNext ${ }^{\circledR}$ Ultra $^{\mathrm{TM}}$ RNA Library Prep Kit for Illumina ${ }^{\circledR}$ (NEB, Ipswich, USA) following the manufacturer's recommendations. Index codes were added to attribute the reads to each sample. Briefly, mRNA was purified from total RNA using poly-T oligo-attached magnetic beads (NEB). Fragmentation was carried out using divalent cations under elevated temperature in a NEB NextFirst ${ }^{\circledR}$ Strand Synthesis Reaction Buffer (5x). First strand cDNA was synthesized using random hexamer primers and M-MuLV Reverse Transcriptase (RNase $\mathrm{H}, \mathrm{NEB})$. Second strand cDNA synthesis was subsequently performed using DNA Polymerase I and RNase H (NEB). The remaining overhangs were converted into blunt ends via exonuclease/polymerase activities (NEB). After adenylation of the $3^{\prime}$ ends of the DNA fragments, NEBNext ${ }^{\circledR}$ adaptors with hairpin loop structure were ligated to DNA. To select fragments of preferentially 250 300 bp in length, the library fragments were purified with AMPure XP system (Beckman Coulter, Brea, USA). Then $3 \mu \mathrm{L}$ USER Enzyme (NEB) was used with size-selected, adaptor-ligated cDNA at $37^{\circ} \mathrm{C}$ for $15 \mathrm{~min}$ followed by $5 \mathrm{~min}$ at $95^{\circ} \mathrm{C}$ before PCR. Subsequently, PCR was performed with Phusion High-Fidelity DNA polymerase (NEB), Universal PCR primers, and Index (X) Primer (NEB). At last, PCR products were purified with AMPure XP system (Beckman Coulter) and library quality was assessed on the Agilent Bioanalyzer 2100 system (Agilent Technologies, Palo Alto, CA, USA). The clustering of the index-coded 
samples was performed on a cBot Cluster Generation System using TruSeq PE Cluster Kit v3-cBot-HS (Illumina Inc.) according to the manufacturer's instructions and sequencing was carried out on an Illumina Hiseq platform $(2 \times 150$ paired-end reads $)$.

Raw Illumina reads were trimmed to remove adaptor sequences, low-quality positions (Phred quality of 20 was used as a cut-off), and reads containing poly-n and reads shorter than $50 \mathrm{bp}$. The resulting high-quality (HQ) reads were deposited at the NCBI SRA Database and used in the downstream analyses. Since there is no reference genome available for $H$. diversicolor supertexta, and only 30-32\% of the reads can be mapped to the only available genome of Haliotis family [36], we applied a reference-independent strategy. De-novo transcriptome assembly was performed with the Trinity assembler (v.2.4.0) [37] setting min_kmer_cov to 2 and all other parameters to defaults. The obtained unigenes were functionally annotation searching for similar hits in seven databases: $\mathrm{Nr}$ (NCBI non-redundant protein sequences, $e$-value $\left.=1 \mathrm{e}^{-5}\right)$, Nt (NCBI non-redundant nucleotide sequences, $e$-value $\left.=1 \mathrm{e}^{-5}\right)$, KO $\left(\right.$ KEGG Orthology database, $e$-value $\left.=1 \mathrm{e}^{-10}\right), \mathrm{GO}\left(\right.$ Gene Ontology, $e$-value $\left.=1 \mathrm{e}^{-6}\right)$, KOG (euKaryotic Ortholog Groups, $e$-value $=1 \mathrm{e}^{-3}$ ), Pfam (Protein family, $e$-value $=1 \mathrm{e}^{-2}$ ), and Swiss-Prot $\left(e\right.$-value $\left.=1 \mathrm{e}^{-5}\right)$.

To produce an expression profile of the HaHV-1 genes, the clean reads were mapped on the HaHV-1 genome (GenBank No. KU096999) with the recently improved annotation [38], applying 0.8 for both length and similarity mapping parameters (CLC Genomics, v.11, Qiagen, Hilden, Germany). The total number of mapped reads was used as a proxy of the HaHV-1 expression value for each of the annotated genes and compared between the 3 experimental groups. In order to classify the viral genes as early or late-expressing genes, we considered the expression ratios between the time points. Briefly, we measured the expression ratio between $24 \mathrm{hpi}$ and $0 \mathrm{hpi}$, and between $60 \mathrm{hpi}$ and $24 \mathrm{hpi}$ for each viral gene, and compared these two values in order to classify the viral genes as 'early-expressed' (the ones with a 24/0 value higher than 10 timed the 60/24 value), 'late-expressed' (the ones with a 60/24 value higher than the $24 / 0$ value), or stable (the remaining expressed genes, i.e., the ones with a $24 / 0$ value slightly higher than the 60/24 value).

Differential expression analysis was performed using the DESeq R package (v.1.10.1). DESeq provides statistical routines for determining differential expression in digital gene expression data using a model based on the negative binomial distribution. The resulting $p$ values were adjusted using the Benjamini and Hochberg's approach for controlling the false discovery rate. Genes with an adjusted $p$-value $<0.05$ found by DESeq were considered as differentially expressed and a pathway enrichment analysis based on the KEGG database annotations was performed on them. GO enrichment analysis was carried out with GOseq $\mathrm{R}$ packages based Wallenius non-central hyper-geometric distribution, which can adjust for gene length bias in differentially expressed genes (DEGs) [39]. Finally, KOBAS software was used to test the statistical enrichment of differential expression genes in KEGG pathways [40].

To validate the expression values obtained by RNA-seq analysis, 8 DEGs were selected for reverse transcription quantitative PCR (RT-qPCR) conformation. These DEGs meet the following 3 criteria: (i) involved in immune-related pathways, (ii) have high/middle expression levels, (iii) perfect PCR efficiencies ranged from $95 \%$ to $100 \%$. Primers were designed with Primer Premier 5 (Table S1) [41]. First strand cDNA was synthesized from $2 \mu \mathrm{g}$ of total RNA with reverse transcriptase (Takara, Shiga, Japan) and random primers, and the resulting products were used as a template for qPCR analysis. qPCR was performed on CFX Connect ${ }^{\mathrm{TM}}$ Real-Time System (Bio-Rad Laboratories, Inc. Hercules, USA) with FastStart Essential DNA Green Master (Roche Diagnostics, Risch-Rotkreuz, Swiss). qPCR reactions were performed in $20 \mu \mathrm{L}$ reaction system under the following thermal cycling conditions: 1 cycle of $95^{\circ} \mathrm{C}$ for $10 \mathrm{~min}$, followed by 40 cycles of $95^{\circ} \mathrm{C}$ for $10 \mathrm{~s}$, and $61^{\circ} \mathrm{C}$ for $33 \mathrm{~s}$ and a melt curve step (from $65^{\circ} \mathrm{C}$, gradually increasing $0.5^{\circ} \mathrm{C} / \mathrm{s}$ to $95^{\circ} \mathrm{C}$, with acquisition data every $1 \mathrm{~s}$ ). Cytc1 were used as the internal standards to normalize the relative expression levels among samples (Zhang SM et al. [42]). All reactions were performed in triplicates and the expression values were calculated as the mean of relative mRNA expression using the $2^{-\Delta \Delta C T}$ method [43]. 


\section{Results and Discussion}

\subsection{Abalone Mortalities and Viral DNA Quantification}

We tested the susceptibility of $H$. diversicolor supertexta to HaHV-1 by performing a controlled infection trial. While no mortality occurred during the acclimation period, after HaHV-1 infection the first mortality occurred at $48 \mathrm{hpi}$ (6.7\% mortality) and developed quickly for the challenged group, reaching $100 \%$ of mortality at $96 \mathrm{hpi}$. The accumulative mortality rates were 13.3, 76.7, and 80.0\% at 60,72 , and $84 \mathrm{hpi}$, respectively. The average amount of viral DNA was estimated as $1.05 \times 10^{6}$ copies $\mathrm{ng}^{-1}$ of total DNA in the mantles of dead abalone. In the HaHV-1 challenged group, the viral DNA exponentially increase after injection and reached averages of $45.9,1.5 \times 10^{6}, 4.3 \times 10^{6}, 5.6 \times 10^{6}$, $2.2 \times 10^{7}, 6.5 \times 10^{7}$, and $8.0 \times 10^{6}$ at $12,24,30,36,48,60$, and $72 \mathrm{hpi}$, respectively. No mortality or viral DNA was detected in the negative controls at the completion of the experiment. The rapid increase of viral DNA, as well as the high mortality rates, indicated that the experimental infection was successful and that the abalone family we used was highly susceptible to HaHV-1 infection.

\subsection{Transcriptome Assembly and Functional Annotation}

A total of $448 \mathrm{M}$ raw reads were generated from the nine sequenced libraries, with $155 \mathrm{M}, 143 \mathrm{M}$, and $150 \mathrm{M}$ reads from MA00h, MA24h, and MA60h groups, respectively (Table 1, NCBI SRA accession number: PRJNA514990 and PRJNA471241). After removing low-quality reads, we de novo assembled $435 \mathrm{M}$ of clean reads. into $2.08 \times 10^{5}$ unigenes, showing a mean length of $1486 \mathrm{bp}$ and an N50 of $2455 \mathrm{bp}$. Among these, $5.25 \times 10^{4}$ unigenes (25.2\%) were in the length range of 200 to $500 \mathrm{bp}, 6.02 \times$ $10^{4}$ unigenes (28.9\%) were between 500 to $1000 \mathrm{bp}, 4.82 \times 10^{4}$ unigenes $(23.2 \%)$ were between 1 to $2 \mathrm{~kb}$, and $4.72 \times 10^{4}$ unigenes $(22.7 \%)$ were longer than $2 \mathrm{~kb}$ (Figure 1 ).

Table 1. Summary of the sequencing and assembly results.

\begin{tabular}{ccccccccc}
\hline Group & Sample & Raw Reads & Clean Reads & Clean Bases & Error (\%) & Q20 (\%) & Q30 (\%) & GC (\%) \\
\hline \multirow{3}{*}{ MA00h } & MA01 & $48,448,828$ & $46,980,888$ & $7.05 \mathrm{G}$ & 0.02 & 96.66 & 91.55 & 44.66 \\
& MA02 & $46,479,558$ & $44,978,850$ & $6.75 \mathrm{G}$ & 0.01 & 97.43 & 93.28 & 45.49 \\
& MA03 & $59,916,192$ & $58,047,078$ & $8.71 \mathrm{G}$ & 0.02 & 97.31 & 93.01 & 44.71 \\
\hline \multirow{3}{*}{ MA24h } & MA13 & $44,682,338$ & $43,431,308$ & $6.51 \mathrm{G}$ & 0.02 & 97.2 & 92.7 & 43.94 \\
& MA14 & $49,698,546$ & $48,290,308$ & $7.24 \mathrm{G}$ & 0.02 & 97.13 & 92.52 & 44.02 \\
& MA15 & $49,009,274$ & $47,443,952$ & $7.12 \mathrm{G}$ & 0.02 & 97.26 & 92.77 & 43.23 \\
\hline \multirow{3}{*}{ MA60h } & MA49 & $51,712,402$ & $50,051,266$ & $7.51 \mathrm{G}$ & 0.02 & 97.17 & 92.69 & 46.16 \\
& MA50 & $41,758,974$ & $40,566,558$ & $6.08 \mathrm{G}$ & 0.02 & 96.7 & 91.62 & 45.68 \\
& MA51 & $56,555,122$ & $54,822,210$ & $8.22 \mathrm{G}$ & 0.01 & 97.37 & 93.12 & 44.81 \\
\hline
\end{tabular}

Since there is no reference genome available for $H$. diversicolor supertexta, or for relative species, the assembled unigenes were subjected to functional annotation by matching them against $\mathrm{Nr}, \mathrm{NT}, \mathrm{KO}$, Swiss-prot, Pfam, GO, and KOG databases. As a result, 131,904 unigenes (63.37\%) were annotated in at least one database, while 6029 unigenes (2.89\%) were annotated in all the seven databases. The matching rates for the specific database were listed in Table 2. Regarding the homology search against the $\mathrm{Nr}$ database, $26.1 \%$ of unigenes had top matches with the owl limpet (Lottia gigantea), followed by $C$. gigas (21.9\%), California sea hare (Aplysia californica) $(17.3 \%)$, purple sea urchin (Strongylocentrotus purpuratus) (1.9\%), Florida lancelet (Branchiostoma floridae) (1.7\%), or with other species (31.0\%) (Table S2). These annotation results mirrored the few sequence information available for the Haliotidae family, since the only transcriptome dataset of $H$. diversicolor supertexta was produced to investigate early development stages (larva and spat) [44]. Therefore, the transcriptomic data generated in the present study will enrich the available resources of this species and will contribute to disclose the abalones' immune-related pathways. 


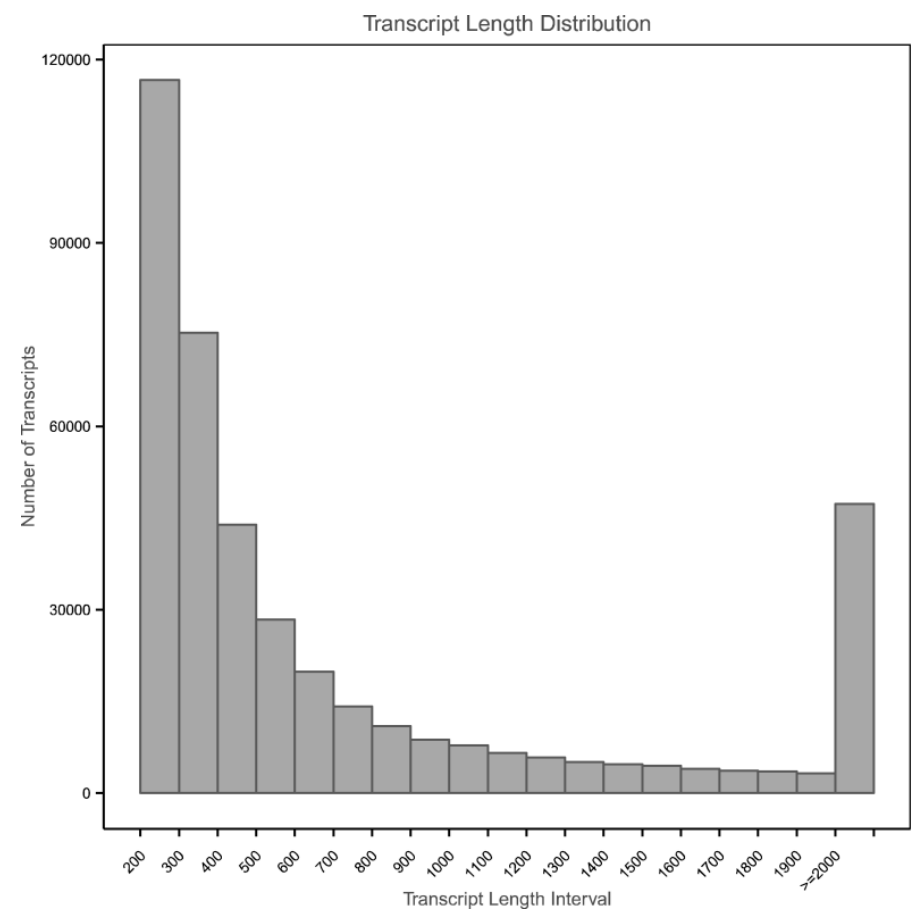

Figure 1. Length distribution of assembled unigenes.

Table 2. Summary statistics of the Haliotis diversicolor supertexta transcriptome annotation.

\begin{tabular}{ccc}
\hline Database & $\begin{array}{c}\text { Number of } \\
\text { Annotated Unigenes }\end{array}$ & $\begin{array}{c}\text { Percentage of } \\
\text { Annotated Unigenes (\%) }\end{array}$ \\
\hline Annotated in Nr & 40,934 & 19.66 \\
Annotated in NT & 71,597 & 34.39 \\
Annotated in KO & 29,322 & 14.08 \\
Annotated in SwissProt & 57,899 & 27.81 \\
Annotated in Pfam & 81,908 & 39.35 \\
Annotated in GO & 82,047 & 39.41 \\
Annotated in KOG & 29,895 & 14.36 \\
Annotated in all databases & 6029 & 2.89 \\
Annotated in at least one database & 131,904 & 63.37 \\
Total unigenes & 208,144 & 100.00 \\
\hline
\end{tabular}

In order to investigate the immune system of $H$. diversicolor supertexta, we further identified genes and pathways involved in immunity. GO classification analysis revealed that 1870 and 22,556 unigenes belong to "immune system process" and "response to stimulus", respectively (Table S3), while KEGG pathways analysis revealed 16 immune-related pathways including 1694 unigenes (Table S4). Additionally, several pathways classified under the general term of as "signal transduction" are also known to be involved in immune processes of mollusks, like the "HIF-1 signaling pathway", "Jak-STAT signaling pathway", "NF-kappa B signaling pathway", and "PI3K-Akt signaling pathway".

\subsection{Analysis of the HaHV-1 Expression Profile}

Read mapping on the HaHV-1 genome identified 1431, 141,047, and 5,872,081 viral reads in the 0 , 24 and 60 hpi samples, respectively. The presence of read mapping on the HaHV-1 genome even in the 0 hpi samples (before injection) is due to their mapping to low-complexity repeats on the viral genome. Total mapped reads per gene, used as a proxy of viral gene expression levels, exhibited negligible values at 0 hpi (0-39), increased values at 24 hpi (1-9012, median 205), and reached the highest values for most of the annotated genes at $60 \mathrm{hpi}(1-175,765$, median 9372, Table S5). Although the viral expression appeared to diffuse along the whole HaHV-1 genome both at 24 and 60 hpi, 
we attempted to classify early and late viral genes. To do this, we measured the expression ratios for each gene between the time points. This analysis revealed only $8 \mathrm{HaHV}-1$ genes with a prevalent 'early' expression trend, namely 7 ORFs with unknown function and one IAP. Most of the HaHV-1 ORFs exhibited somewhat stable expression trends among the tested time points (64 genes) or a preferential expression at $60 \mathrm{hpi}$ ( 45 genes). These results are in agreement with the expression profiles that we recently published based on 37 selected HaHV-1 ORFs [38]. Although in-vivo analysis prevents the possibility to have synchronous viral infections due to the variability within cells and animals, this analysis identified viral genes preferentially induced in the early infection and can be used for future comparisons with similar viruses. Up-regulated viral IAPs were reported also for in bivalve species infected with OsHV-1 [25-27]. In a detailed study recently published, de Lorgeril et al. (2018) analyzed transcriptomic features of susceptible versus OsHV-1-resistant C. gigas families and showed that the expressions of both endogenous and viral IAPs were significantly up-regulated in susceptible families starting from $24 \mathrm{hpi}$, while IAPs are not modulated in the resistant family. They suggested that this difference can explain a delayed and inefficient antiviral response of the susceptible oysters [27].

\subsection{Analysis of DEGs Related to Immune Activities}

Based on differential expression analysis, pairwise comparisons were carried out among the three groups (MA00h, MA24h, and MA60h). A total of 7227 and 6914 unigenes were classified as significantly up-regulated or down-regulated in at least one comparison pair, whereas only 10 up-regulated and 22 down-regulated DEGs are common to all comparisons (Figure 2, Table S6). In details, the comparison between MA60h/MA00h vs. MA60h/MA24h exhibited the highest number (1730) of up-regulated DEGs, followed by that of MA60h/MA00h vs. MA24h/MA00h (240), and between MA60h/MA24h vs. MA24h/MA00h (11). The number of DEGs for each comparison is visualized in Figure 2d. It is interesting that 4601 up-regulated and 5426 down-regulated DEGs were identified when comparing MA60h and MA24h groups, which are higher numbers than those obtained comparing MA60h and MA00h groups (3720 up-regulated and 2392 down-regulated DEGs).
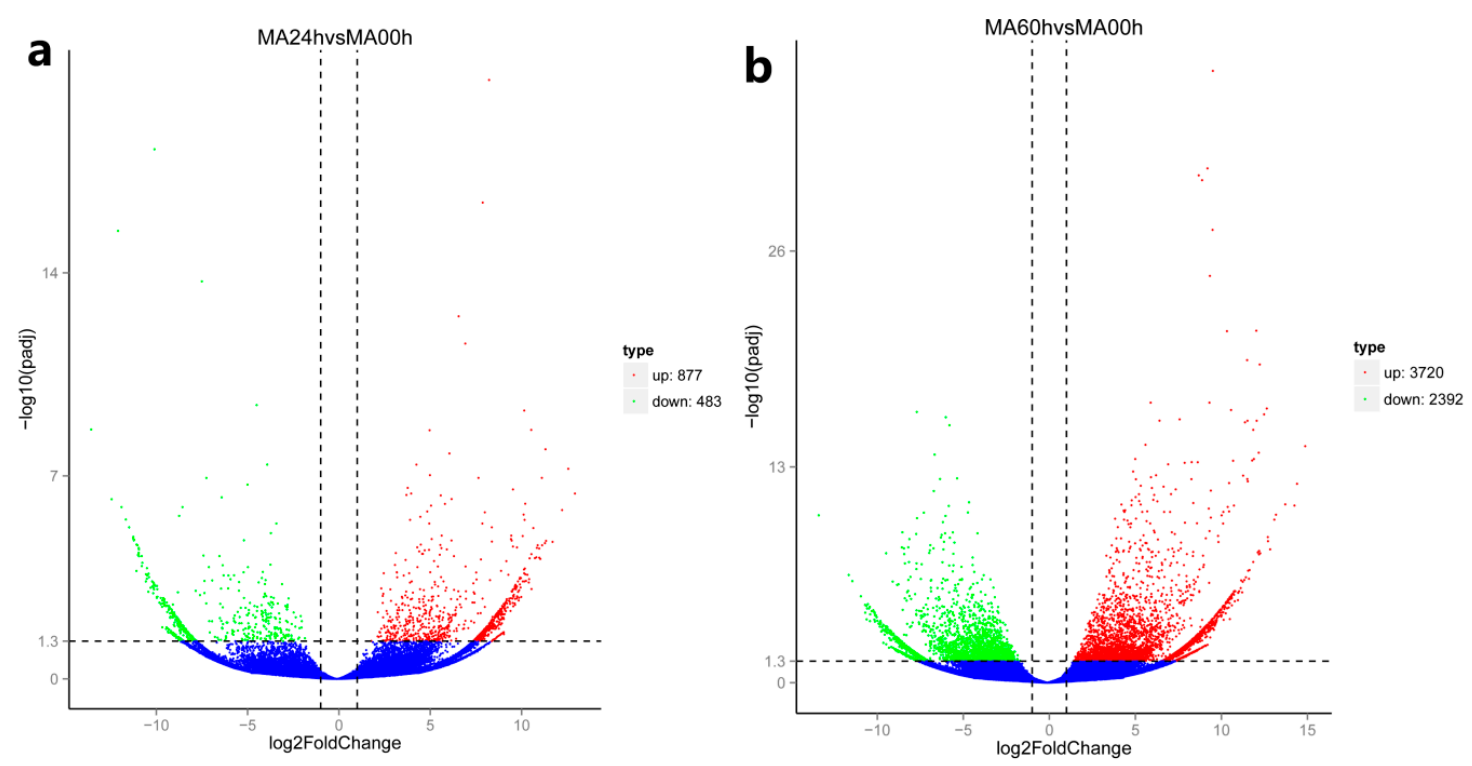

Figure 2. Cont. 

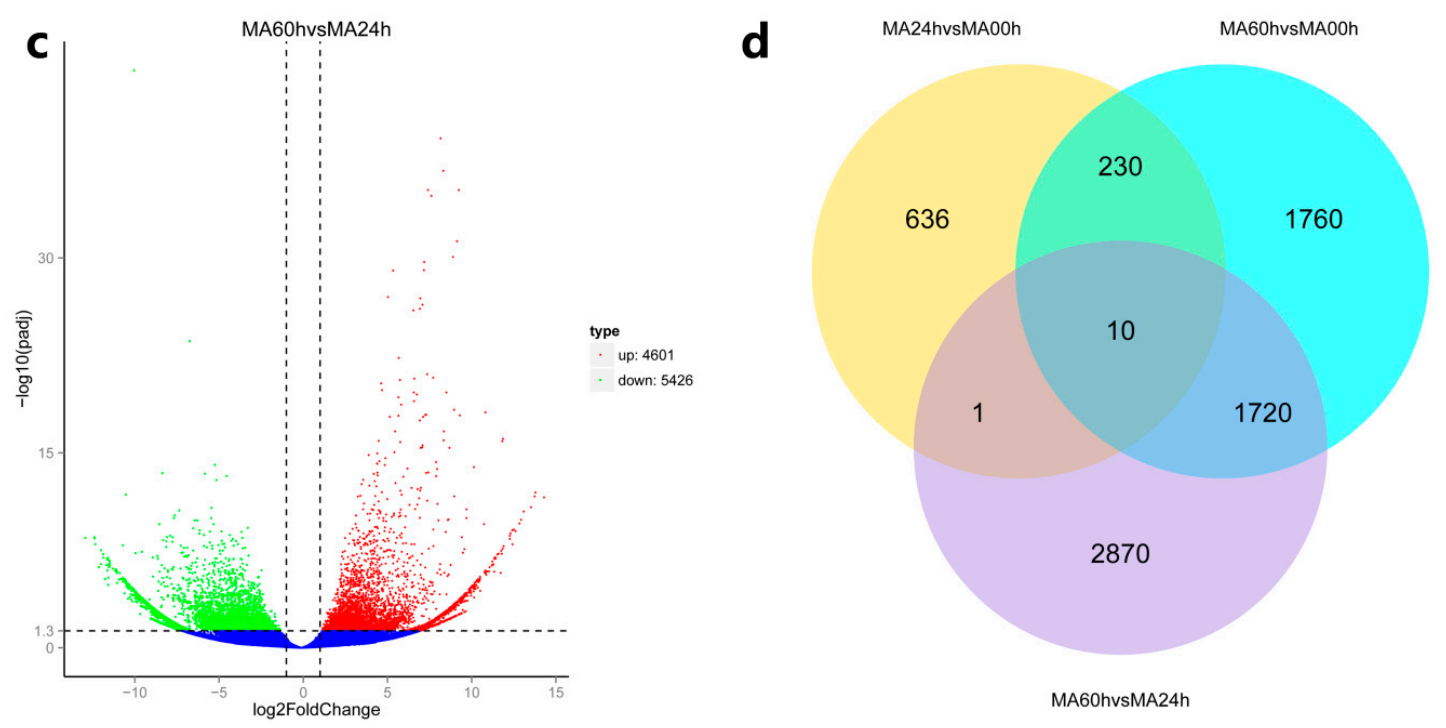

Figure 2. Volcano and Venn plots of differentially expressed genes (DEGs). (a) Volcano plots of DEGs comparing MA24h and MA00h groups; (b) Volcano plots of DEGs comparing MA60h and MA00h groups; (c) Volcano plots of DEGs comparing MA60h and MA24h groups; (d) Venn graph of DEGs among the different comparisons. Red spots in panels (a), (b), and (c) depicted over-DEGs, green spots under-DEGs, whereas blue spots referred to non-differentially expressed genes.

\subsubsection{The Delayed Immune Response of Abalone to HaHV-1 Infection}

Although 877 and 483 unigenes were identified as up-regulated and down-regulated when we compared MA24h vs. MA00h groups, no GO terms with significant changes ( $p$-value $<0.05$ ) were identified (Table S7). Accordingly, KEGG pathway enrichment analysis showed no significantly up-regulated pathway ( $q$-value $<0.05$ ) (Figure 3a), with only two down-regulated items found significantly enriched (Neuroactive ligand-receptor interaction and ECM-receptor interaction, $q$-value $=0.0395)$. These results demonstrated that the transcriptome at $24 \mathrm{hpi}$ is similar to the control ( $0 \mathrm{hpi})$. No immune-related genes with an increased expression were identified, although the viral DNA increased up to $1.5 \times 10^{6} \mathrm{GE} / \mathrm{ng}^{-1}$ total DNA and HaHV-1 transcriptome analysis showed the active status of the virus (Table S5). Viral DNA continued to increase, and abalones start to die at $48 \mathrm{hpi}$, whereas the viral infection burden reaches the peak at $60 \mathrm{hpi}$. At this point, many up-regulated unigenes associated with antiviral responses were detected. However, this intense but delayed antiviral response was inefficient to protect the animals, and approximately $50 \%$ mortality occurred within the following $12 \mathrm{~h}$ (from $60 \mathrm{hpi}$ to $72 \mathrm{hpi}$ ). This temporal pattern of infection is similar to the one observed for highly susceptible $C$. gigas families, i.e., the deficiency of early antiviral response against OsHV-1 and an intense but inefficient later antiviral responses [27].

The lack of early immune response (before $24 \mathrm{hpi}$ ) associated with a considerable viral load is unusual in virally-infected mollusks. This result cannot be explained by the high susceptibility of abalone alone. Actually, the early immune response has been reported even for the $C$. gigas family with the highest susceptibility to OsHV-1 infection, although the level was significantly lower than that of resistant families [16,27]. The lack of immune response observed here may, therefore, be explained by more effective HaHV-1 immune evasion strategies. Higher vertebrate herpesviruses are equipped with sophisticated immune evasion strategies, which include the establishment of latency, molecular mimicry, virus-induced immunosuppression, and modulation of immune recognition structure $[9,10]$. However, there is little information about the immune evasion strategies deployed by the invertebrate herpesvirus (HaHV-1 and OsHV-1) [16]. Reasonable predictions about these strategies are also impossible due to the low genetic relatedness between them [2,45]. In addition to the immune evasion skills mentioned above, herpesvirus could also hide by adopting more cryptic ways during their spreading. The herpesvirus depends on two fundamental models to enter into the target cells, 
either by diffusion through the extracellular space (cell-free mode) or by direct cell-cell contact (cell-cell mode) [46,47]. Both mechanisms of viral spread have advantages and disadvantages [47]. The cell-free mode is often inefficient and more vulnerable to the host immune surveillance, because they have to overcome cellular barriers in both donor and target cells. However, the cell-free mode is necessary for spread across long distances and to a new host. The cell-cell mode is very efficient because the barriers could be circumvented by direct cell-to-cell transmission, while the cell-cell mode could be only used within an organism [47]. The cell-cell mode has been recognized as a means to avoid neutralizing antibodies by vertebrate herpesvirus [48]. No data is available about the spreading mechanisms of HaHV-1 within an abalone or among different individuals. However, fewer cases of enveloped HaHV-1 particles were reported $[1,5,49,50]$ compared to that of enveloped OsHV-1 particles [51-53]. It is, therefore, possible that the cell-cell spreading was more frequently employed by HaHV-1, and could be partially responsible for the lack of early immune response.
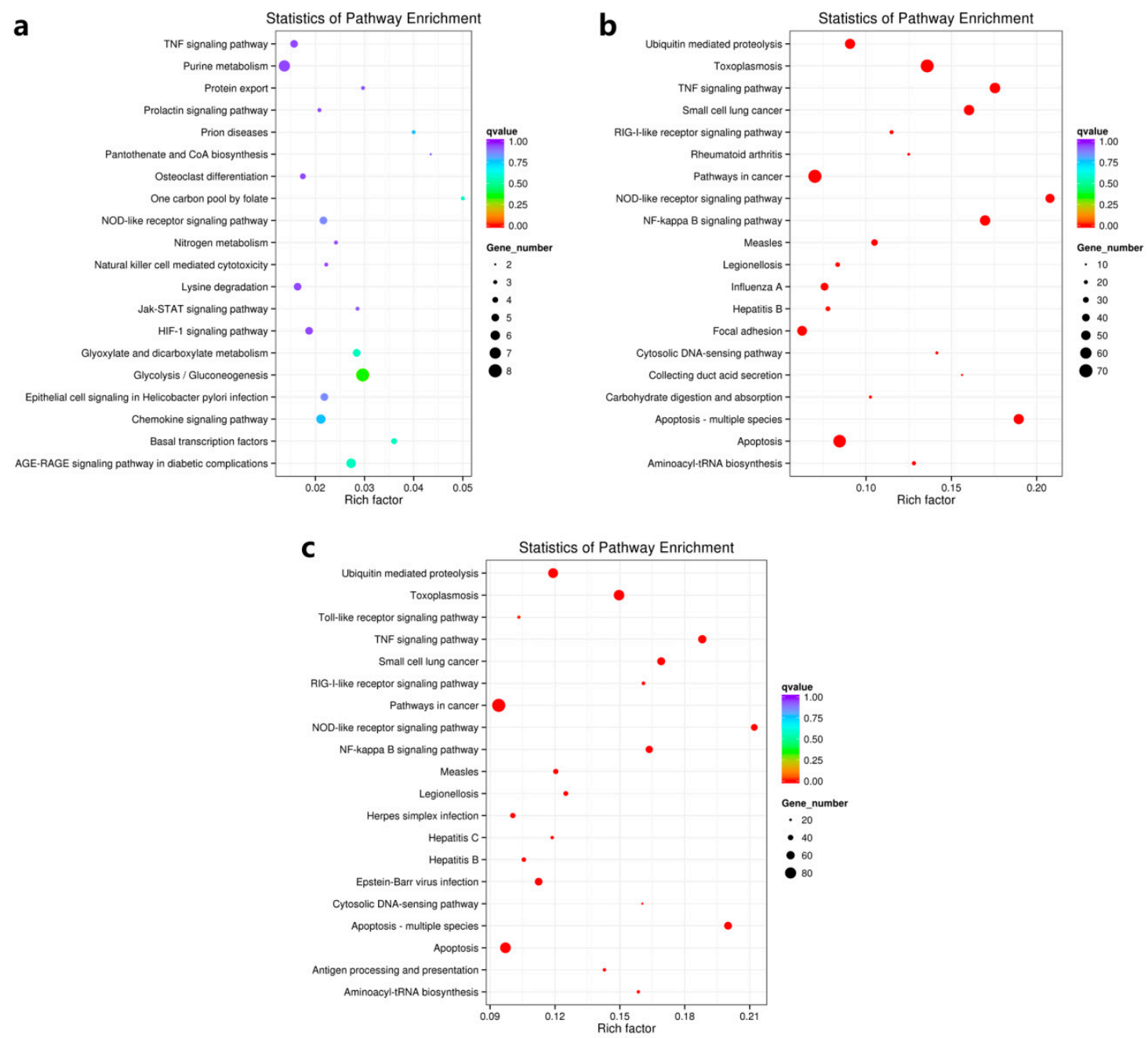

Figure 3. Scatter plot of KEGG enrichment analysis of differentially expressed genes (DEGs) between MA24h and MA00h (a), MA60h and MA00h (b) and MA60h and MA24h (c). Top 20 up-regulated KEGG pathways were displayed. The larger the Rich factor, the greater the degree of enrichment. The value range of $q$ value is $(0,1)$. The closer it is to zero, the more significant the enrichment is. Pathways with $q \leq 0.05$ are defined as pathways that are significantly enriched in DEGs.

\subsubsection{A Rich Set of Immune-Related Pathways in Abalone in Response to HaHV-1 Infection}

Between MA60h and MA00h groups, there were 3720 up-regulated and 2392 down-regulated unigenes, respectively. GO term enrichment analysis showed that most of them were classified into 
two GO categories (biological process and molecular function) with a $p$-value $<0.05$ (Table S8). Further KEGG pathway analysis classified the up-regulated DEGs into 261 pathways (Table S9), and 26 of them were found to be significantly up-regulated with a $q$-value $<0.05$ (Table 3). The top 20 most up-regulated pathway terms are shown in Figure $3 \mathrm{~b}$. Among the 26 significantly enriched pathways, 21 were associated with immunity and disease process and five were related metabolic process. Comparison of MA60h and MA24h groups revealed similar over-expression patterns with MA60h and MA00h groups (Table 3 and Figure 3). These results further indicated that MA24h and MA00h groups have similar transcriptomic profiles and the lack of immunity at $24 \mathrm{hpi}$.

Table 3. Significant up-regulated pathways in Haliotis diversicolor supertexta at 60 hpi.

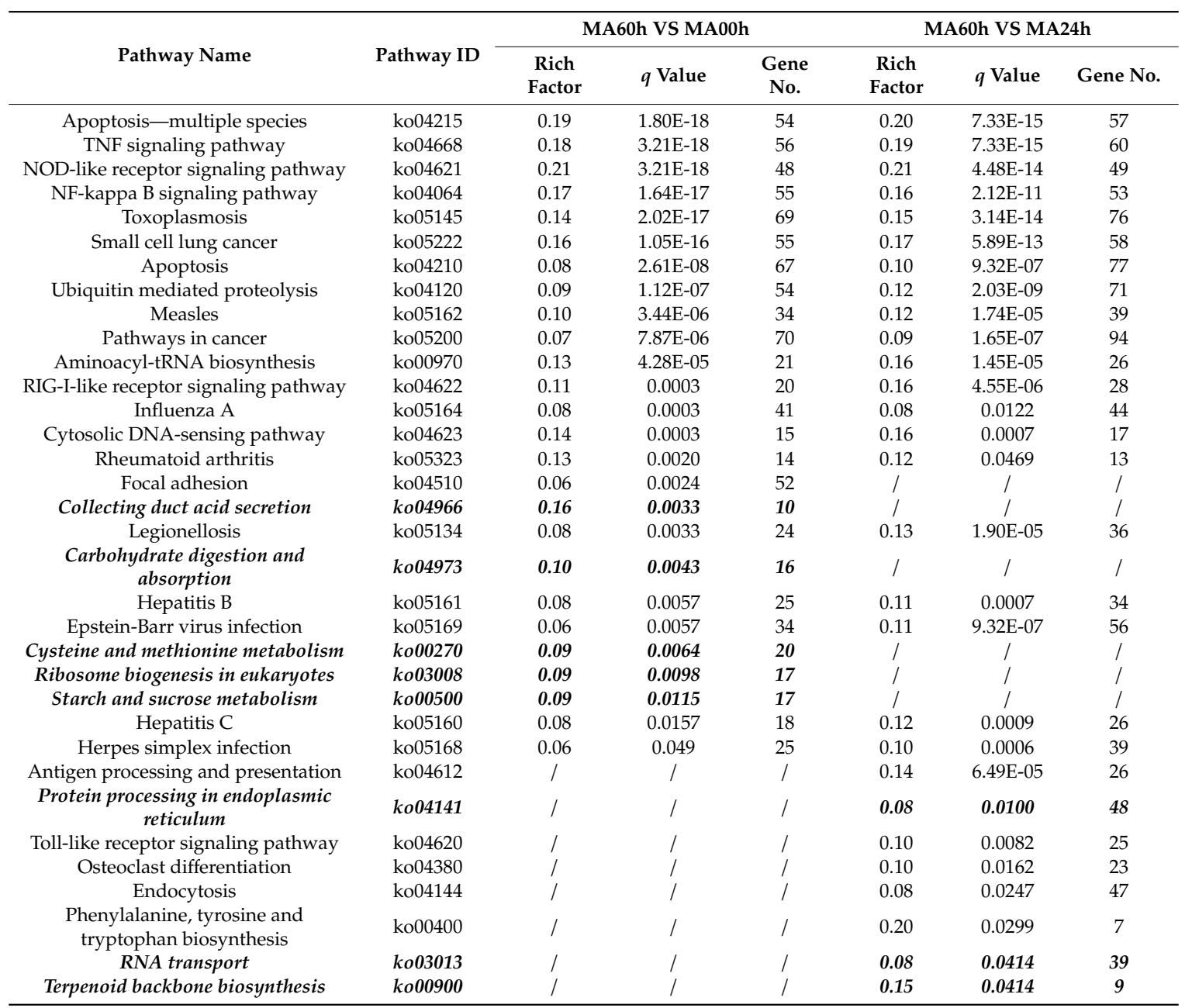

The items printed in normal were pathways associated with immunity and disease process due to HaHV-1 infection, the pathways printed in bold and italic were pathways associated with metabolic process and proposed to be up-regulated due to the viral infection. The forward slash ' $/$ ' indicated the absence of data, since thesepathways were not significantly up-regulated at the specific time points compared to the control group (MA00h).

Ten of the 21 immuno-associated pathways are involved in immunity against virus infection. Seven of these pathways are also well-known in mollusks' immune defense against pathogenic infections, which include apoptosis, TNF, NOD-like, NF-kappa B, Ubiquitin-mediated proteolysis, RIG-I-like, etc. [16,24-26]. Another three pathways, including aminoacyl-tRNA biosynthesis [54], focal adhesion [55], and cytosolic DNA-sensing pathway [56], have been reported to be associated with antiviral response in vertebrate animals. These results indicated that there are a rich set of genes involved in the antiviral response in abalone. The specific role of these pathways in the antiviral process needs further investigation. A considerable number of immune-related genes were also detected in susceptible C. gigas compared to resistant individuals after $24 \mathrm{~h}$ post-infection [27]. This kind of 
massive and extensive reprogramming of transcriptomes is unusual for organisms and it will demand a huge amount of energy, which may accelerate the disease process [57]. Accordingly, we identified five up-regulated pathways related to metabolic process, and approximately $50 \%$ mortality occurred between 60 and $72 \mathrm{hpi}$. These results indicate that late activation of immune genes, although in large quantities, was insufficient to conquer the virus and maintain the cellular homeostasis. As a result, several pathways involved in the disease process were over-represented, which indicated that cell and tissue lesions have fully developed, and stood for signals of the immune failure.

A rich gene set associated directly with viral replication and assembly were also identified in challenged abalone at 60 hpi. GO term enrichment analysis identified 11 terms interpreted as viral tegument proteins with a significant $p$-value $=0.0161$ compared to the negative control. Additionally, many viral structure proteins associated with viral envelop, membrane, and capsid were also over-expressed at $60 \mathrm{hpi}$ (Table S8). Viral structural proteins are often necessary for the activation of host antiviral response [58]. Therefore, we proposed that during HaHV-1 infection, more and more host cells died, and the accumulated structural proteins of the virus were released out of cells, which should be responsible for the massive enrichment of host immune-related genes.

\subsection{Validation of RNA-Seq Results by RT-qPCR}

Since the detection limit of RT-qPCR is relatively low compared to RNA-Seq, only unigenes with high/middle expression levels could be used for RT-qPCR validation. The relative expression values of RT-qPCR and RNA-seq were described as the $\log _{2}$ (fold change). Our results show that 22 out of the total 24 selected genes exhibited a concordant trend between RT-qPCR and RNA-seq expression values. The correlation between the expression levels of RT-qPCR and RNA-seq are shown in Figure S1.

\section{Conclusions}

In the present study, we sequenced the transcriptomes of H. diversicolor supertexta infected with HaHV-1 and we investigated virus-host interactions at a molecular level. This work represents the first step towards elucidating the immune mechanisms of abalone against HaHV-1. Unexpected delays of the abalone antiviral response suggested that HaHV-1 has evolved effective strategies to evade early immune surveillance. The over-expressed host genes at the late stages of the infection will provide useful information to understand the molecular mechanisms of the antiviral response of gastropod against dsDNA viruses.

Supplementary Materials: The following are available online at http://www.mdpi.com/1999-4915/11/4/383/s1, Figure S1. Validation of transcriptomic differentially expressed genes (DEGs) by RT-qPCR. Table S1. Primers used for RT-qPCR validation of RNA-Seq results. Table S2. Functional annotation of the assembled unigenes. Table S3. GO annotation of the Haliotis diversicolor supertexta transcriptome. Table S4. KEGG annotation of the Haliotis diversicolor supertexta transcriptome. Table S5. Expression of HaHV-1 genes. Table S6. List of differentially expressed genes (DEGs) with annotations and expression values Table S7. GO annotation for up-regulated DEGs between MA24h and MA00h groups Table S8. GO annotation for up-regulated DEGs between MA60h and MA00h groups Table S9. KEGG pathway assignment up-regulated DEGs between MA60h and MA00h groups

Author Contributions: Conceptualization, C.-M.B. and U.R.; methodology, C.-M.B., S.-M.Z., Y.-N.L., U.R.; software, U.R. and C.-M.B.; validation, C.-M.W., L.-S.X.; writing-original draft preparation, C.-M.B. and U.R.; writing-review and editing, C.-M.B. and U.R.; supervision, C.-M.W.; funding acquisition, C.-M.B., U.R., and C.-M.W.

Funding: C.-M.B. was supported by the Laboratory for Marine Fisheries Science and Food Production Processes, grant number 2016LMFS-B16. C.-M.W. was supported by China Agriculture Research System, grant number CARS-49. U.R. was supported by a biennial grant of the University of Padova, UNIPD-BIRD 168432.

Acknowledgments: We are grateful to Wei-Wei You from Xiamen University for providing us Haliotis diversicolor supertexta specimen and technical assistance about abalone cultivation. We also thank Jie Shi and Wen-Hui Gao for maintaining of abalone and collecting samples.

Conflicts of Interest: The authors declare no conflict of interest. 


\section{References}

1. Chang, P.H.; Kuo, S.T.; Lai, S.H.; Yang, H.S.; Ting, Y.Y.; Hsu, C.L.; Chen, H.C. Herpes-like virus infection causing mortality of cultured abalone Haliotis diversicolor supertexta in Taiwan. Dis. Aquat. Organ. 2005, 65, 23-27. [CrossRef] [PubMed]

2. Savin, K.W.; Cocks, B.G.; Wong, F.; Sawbridge, T.; Cogan, N.; Savage, D.; Warner, S. A neurotropic herpesvirus infecting the gastropod, abalone, shares ancestry with oyster herpesvirus and a herpesvirus associated with the amphioxus genome. Virol. J. 2010, 7, 1-9. [CrossRef] [PubMed]

3. Hooper, C.; Hardy-Smith, P.; Handlinger, J. Ganglioneuritis causing high mortalities in farmed Australian abalone (Haliotis laevigata and Haliotis rubra). Aust. Vet. J. 2007, 85, 188-193. [CrossRef] [PubMed]

4. Wang, J.; Guo, Z.; Feng, J.; Liu, G.; Xu, L.; Chen, B.; Pan, J. Virus infection in cultured abalone, Haliotis diversicolor Reeve in Guangdong Province, China. J. Shellfish Res. 2004, 23, 1163-1168.

5. Bai, C.M.; Li, Y.N.; Chang, P.H.; Jiang, J.Z.; Xin, L.S.; Li, C.; Wang, J.Y.; Wang, C.M. Susceptibility of two abalone species, Haliotis diversicolor supertexta and Haliotis discus hannai, to Haliotid herpesvirus 1 infection. J. Invertebr. Pathol. 2019, 160, 26-32. [CrossRef] [PubMed]

6. Le Deuff, R.M.; Renault, T. Purification and partial genome characterization of a herpes-like virus infecting the Japanese oyster, Crassostrea gigas. J. Gen. Virol. 1999, 80, 1317-1322. [CrossRef]

7. Davison, A.J.; Trus, B.L.; Cheng, N.; Steven, A.C.; Watson, M.S.; Cunningham, C.; Le Deuff, R.M.; Renault, T. A novel class of herpesvirus with bivalve hosts. J. Gen. Virol. 2005, 86, 41-53. [CrossRef] [PubMed]

8. Davison, A.J. Evolution of the herpesviruses. Vet. Microbiol. 2002, 86, 69-88. [CrossRef]

9. Banks, T.A.; Rouse, B.T. Herpesviruses-Immune escape artists? Clin. Infect. Dis. 1992, 14, $933-941$. [CrossRef]

10. Griffin, B.D.; Verweij, M.C.; Wiertz, E.J. Herpesviruses and immunity: The art of evasion. Vet. Microbiol. 2010, 143, 89-100. [PubMed]

11. Verweij, M.C.; Ressing, M.E.; Knetsch, W.; Quinten, E.; Halenius, A.; van Bel, N.; Hengel, H.; Drijfhout, J.W.; van Hall, T.; Wiertz, E.J. Inhibition of mouse TAP by immune evasion molecules encoded by non-murine herpesviruses. Mol. Immunol. 2011, 48, 835-845. [CrossRef]

12. Ma, G.; Azab, W.; Osterrieder, N. Equine herpesviruses type 1 (EHV-1) and 4 (EHV-4)-masters of co-evolution and a constant threat to equids and beyond. Vet. Microbiol. 2013, 167, 123-134. [CrossRef] [PubMed]

13. Horst, D.; Ressing, M.E.; Wiertz, E.J. Exploiting human herpesvirus immune evasion for therapeutic gain: Potential and pitfalls. Immunol. Cell Biol. 2011, 89, 359-366. [CrossRef] [PubMed]

14. Green, T.J.; Speck, P. Antiviral Defense and Innate Immune Memory in the Oyster. Viruses 2018, $10,133$. [CrossRef] [PubMed]

15. Moreau, P.; Moreau, K.; Segarra, A.; Tourbiez, D.; Travers, M.A.; Rubinsztein, D.C.; Renault, T. Autophagy plays an important role in protecting Pacific oysters from OsHV-1 and Vibrio aestuarianus infections. Autophagy 2015, 11, 516-526. [CrossRef] [PubMed]

16. Segarra, A.; Mauduit, F.; Faury, N.; Trancart, S.; Dégremont, L.; Tourbiez, D.; Haffner, P.; Barbosa-Solomieu, V.; Pepin, J.F.; Travers, M.A.; et al. Dual transcriptomics of virus-host interactions: Comparing two Pacific oyster families presenting contrasted susceptibility to ostreid herpesvirus 1. BMC Genomics 2014, 15, 580. [CrossRef] [PubMed]

17. Renault, T.; Faury, N.; Barbosa-Solomieu, V.; Moreau, K. Suppression substractive hybridisation (SSH) and real time PCR reveal differential gene expression in the Pacific cupped oyster, Crassostrea gigas, challenged with Ostreid herpesvirus 1. Dev. Comp. Immunol. 2011, 35, 725-735. [CrossRef]

18. Segarra, A.; Baillon, L.; Tourbiez, D.; Benabdelmouna, A.; Faury, N.; Bourgougnon, N.; Renault, T. Ostreid herpesvirus type 1 replication and host response in adult Pacific oysters, Crassostrea gigas. Vet. Res. 2014, 45, 103. [CrossRef]

19. Bai, C.M.; Morga, B.; Rosani, U.; Shi, J.; Li, C.; Xin, L.S.; Wang, C.M. Long-range PCR and high-throughput sequencing of Ostreid herpesvirus 1 indicate high genetic diversity and complex evolution process. Virology 2019, 526, 81-90. [CrossRef]

20. Burioli, E.A.V.; Prearo, M.; Houssin, M. Complete genome sequence of Ostreid herpesvirus type 1 microVar isolated during mortality events in the Pacific oyster Crassostrea gigas in France and Ireland. Virology 2017, 509, 239-251. [CrossRef] 
21. Martenot, C.; Travaille, E.; Lethuillier, O.; Lelong, C.; Houssin, M. Genome exploration of six variants of the Ostreid Herpesvirus 1 and characterization of large deletion in OsHV-1 mu Var specimens. Virus Res. 2013, 178, 462-470. [CrossRef]

22. Renault, T.; Moreau, P.; Faury, N.; Pepin, J.F.; Segarra, A.; Webb, S. Analysis of clinical ostreid herpesvirus 1 (Malacoherpesviridae) specimens by sequencing amplified fragments from three virus genome areas. J. Virol. 2012, 86, 5942-5947. [CrossRef]

23. Martenot, C.; Oden, E.; Travaille, E.; Malas, J.P.; Houssin, M. Detection of different variants of Ostreid Herpesvirus 1 in the Pacific oyster, Crassostrea gigas between 2008 and 2010. Virus Res. 2011, 160, 25-31. [CrossRef]

24. Rosani, U.; Varotto, L.; Domeneghetti, S.; Arcangeli, G.; Pallavicini, A.; Venier, P. Dual analysis of host and pathogen transcriptomes in ostreid herpesvirus 1-positive Crassostrea gigas. Environ. Microbiol. 2015, 17, 4200-4212. [CrossRef]

25. He, Y.; Jouaux, A.; Ford, S.E.; Lelong, C.; Sourdaine, P.; Mathieu, M.; Guo, X. Transcriptome analysis reveals strong and complex antiviral response in a mollusc. Fish. Shellfish Immunol. 2015, 46, 131-144. [CrossRef]

26. Bai, C.M.; Rosani, U.; Xin, L.S.; Li, G.Y.; Li, C.; Wang, Q.C.; Wang, C.M. Dual transcriptomic analysis of Ostreid herpesvirus 1 infected Scapharca broughtonii with an emphasis on viral anti-apoptosis activities and host oxidative bursts. Fish. Shellfish Immun. 2018, 82, 554-564. [CrossRef]

27. De Lorgeril, J.; Lucasson, A.; Petton, B.; Toulza, E.; Montagnani, C.; Clerissi, C.; Vidal-Dupiol, J.; Chaparro, C.; Galinier, R.; Escoubas, J.M.; et al. Immune-suppression by OsHV-1 viral infection causes fatal bacteraemia in Pacific oysters. Nat. Commun. 2018, 9, 4215. [CrossRef] [PubMed]

28. Martenot, C.; Gervais, O.; Chollet, B.; Houssin, M.; Renault, T. Haemocytes collected from experimentally infected Pacific oysters, Crassostrea gigas: Detection of ostreid herpesvirus 1 DNA, RNA, and proteins in relation with inhibition of apoptosis. PLoS ONE 2017, 12, e0177448. [CrossRef] [PubMed]

29. Morga, B.; Faury, N.; Guesdon, S.; Chollet, B.; Renault, T. Haemocytes from Crassostrea gigas and OsHV-1: A promising in vitro system to study host/virus interactions. J. Invertebr. Pathol. 2017, 150, 45-53. [CrossRef]

30. Martenot, C.; Segarra, A.; Baillon, L.; Faury, N.; Houssin, M.; Renault, T. In situ localization and tissue distribution of ostreid herpesvirus 1 proteins in infected Pacific oyster, Crassostrea gigas. J. Invertebr. Pathol. 2016, 136, 124-135. [CrossRef]

31. You, Y.; Cheng, A.C.; Wang, M.S.; Jia, R.Y.; Sun, K.F.; Yang, Q.; Wu, Y.; Zhu, D.; Chen, S.; Liu, M.F.; et al. The suppression of apoptosis by alpha-herpesvirus. Cell Death Dis. 2017, 8, e2749. [CrossRef] [PubMed]

32. Nguyen, M.L.; Blaho, J.A. Apoptosis during herpes simplex virus infection. Adv. Virus Res. 2007, 69, 67-97. [PubMed]

33. Goodkin, M.L.; Morton, E.R.; Blaho, J.A. Herpes simplex virus infection and apoptosis. Int. Rev. Immunol. 2004, 23, 141-172. [CrossRef]

34. Arzul, I.; Corbeil, S.; Morga, B.; Renault, T. Viruses infecting marine molluscs. J. Invertebr. Pathol. 2017, 147, 118-135. [CrossRef] [PubMed]

35. Schikorski, D.; Renault, T.; Saulnier, D.; Faury, N.; Moreau, P.; Pepin, J.F. Experimental infection of Pacific oyster Crassostrea gigas spat by ostreid herpesvirus 1: Demonstration of oyster spat susceptibility. Vet. Res. 2011, 42, 27. [CrossRef] [PubMed]

36. Nam, B.H.; Kwak, W.; Kim, Y.O.; Kim, D.G.; Kong, H.J.; Kim, W.J.; Kang, J.H.; Park, J.Y.; An, C.M.; Moon, J.Y.; et al. Genome sequence of pacific abalone (Haliotis discus hannai): The first draft genome in family Haliotidae. Gigascience 2017, 6, 1-8. [CrossRef] [PubMed]

37. Grabherr, M.G.; Haas, B.J.; Yassour, M.; Levin, J.Z.; Thompson, D.A.; Amit, I.; Adiconis, X.; Fan, L.; Raychowdhury, R.; Zeng, Q.D.; et al. Full-length transcriptome assembly from RNA-Seq data without a reference genome. Nat. Biotechnol. 2011, 29, 644-652. [CrossRef]

38. Bai, C.M.; Rosani, U.; Li, Y.N.; Zhang, S.M.; Xin, L.S.; Wang, C.M. RNA-seq of HaHV-1-infected abalones reveals a common transcriptional signature of Malacoherpesviruses. Sci Rep. 2019, 9, 938. [CrossRef]

39. Young, M.D.; Wakefield, M.J.; Smyth, G.K.; Oshlack, A. Gene ontology analysis for RNA-seq: Accounting for selection bias. Genome Biol. 2010, 11, R14. [CrossRef]

40. Mao, X.Z.; Cai, T.; Olyarchuk, J.G.; Wei, L.P. Automated genome annotation and pathway identification using the KEGG Orthology (KO) as a controlled vocabulary. Bioinformatics 2005, 21, 3787-3793. [CrossRef]

41. Singh, V.K.; Mangalam, A.K.; Dwivedi, S.; Naik, S. Primer premier: Program for design of degenerate primers from a protein sequence. Biotechniques 1998, 24, 318-319. [CrossRef] [PubMed] 
42. Zhang, S.-M.; Bai, C.-M.; Li, Y.N.; Xin, L.-S.; Wang, C.-M. Selection of reference genes as internal control for gene expression in adult abalone Haliotis diversicolor supertexta. J. Invertebr. Pathol.. submitted.

43. Livak, K.J.; Schmittgen, T.D. Analysis of relative gene expression data using real-time quantitative PCR and the 2(T)(-Delta Delta C) method. Methods 2001, 25, 402-408. [CrossRef]

44. Huang, Z.X.; Chen, Z.S.; Ke, C.H.; Zhao, J.; You, W.W.; Zhang, J.; Dong, W.T.; Chen, J. Pyrosequencing of Haliotis diversicolor transcriptomes: Insights into early developmental molluscan gene expression. PLoS ONE 2012, 7, e51279. [CrossRef] [PubMed]

45. Mushegian, A.; Karin, E.L.; Pupko, T. Sequence analysis of malacoherpesvirus proteins: Pan-herpesvirus capsid module and replication enzymes with an ancient connection to "Megavirales". Virology 2018, 513, 114-128. [CrossRef] [PubMed]

46. Mettenleiter, T.C. Initiation and spread of alpha-herpesvirus infections. Trends Microbiol. 1994, 2, 2-4. [CrossRef]

47. Zhong, P.; Agosto, L.M.; Munro, J.B.; Mothes, W. Cell-to-cell transmission of viruses. Curr. Opin. Virol. 2013, 3, 44-50. [CrossRef]

48. Carmichael, J.C.; Yokota, H.; Craven, R.C.; Schmitt, A.; Wills, J.W. The HSV-1 mechanisms of cell-to-cell spread and fusion are critically dependent on host PTP1B. PLoS Pathog. 2018, 14, e1007054. [CrossRef]

49. Corbeil, S.; McColl, K.A.; Williams, L.M.; Mohammad, I.; Hyatt, A.D.; Crameri, S.G.; Fegan, M.; Crane, M.S. Abalone viral ganglioneuritis: Establishment and use of an experimental immersion challenge system for the study of abalone herpes virus infections in Australian abalone. Virus Res. 2012, 165, 207-213. [CrossRef]

50. Hooper, C.; Slocombe, R.; Day, R.; Crawford, S. Leucopenia associated with abalone viral ganglioneuritis. Aust. Vet. J. 2012, 90, 24-28. [CrossRef]

51. Bai, C.; Gao, W.; Wang, C.; Yu, T.; Zhang, T.; Qiu, Z.; Wang, Q.; Huang, J. Identification and characterization of ostreid herpesvirus 1 associated with massive mortalities of Scapharca broughtonii broodstocks in China. Dis. Aquat. Organ. 2016, 118, 65-75. [CrossRef]

52. Renault, T.; Le Deuff, R.M.; Chollet, B.; Cochennec, N.; Gerard, A. Concomitant herpes-like virus infections in hatchery-reared larvae and nursery-cultured spat Crassostrea gigas and Ostrea edulis. Dis. Aquat. Organ. 2000, 42, 173-183. [CrossRef] [PubMed]

53. Hine, P.; Thorne, T. Replication of herpes-like viruses in haemocytes of adult flat oysters Ostrea angasi an ultrastructural study. Dis. Aquat. Organ. 1997, 29, 189-196. [CrossRef]

54. Abergel, C.; Rudinger-Thirion, J.; Giege, R.; Claverie, J.M. Virus-encoded aminoacyl-tRNA synthetases: Structural and functional characterization of mimivirus TyrRS and MetRS. J. Virol. 2007, 81, 12406-12417. [CrossRef] [PubMed]

55. Fouquet, B.; Nikolic, J.; Larrous, F.; Bourhy, H.; Wirblich, C.; Lagaudriere-Gesbert, C.; Blondel, D. Focal Adhesion Kinase Is Involved in Rabies Virus Infection through Its Interaction with Viral Phosphoprotein P. J. Virol. 2015, 89, 1640-1651. [CrossRef]

56. Sun, C.L.; Schattgen, S.A.; Pisitkun, P.; Jorgensen, J.P.; Hilterbrand, A.T.; Wang, L.J.; West, J.A.; Hansen, K.; Horan, K.A.; Jakobsen, M.R.; et al. Evasion of Innate Cytosolic DNA Sensing by a Gammaherpesvirus Facilitates Establishment of Latent Infection. J. Virol. 2015, 194, 1819-1831. [CrossRef]

57. Allam, B.; Raftos, D. Immune responses to infectious diseases in bivalves. J. Invertebr. Pathol. 2015, 131, 121-136. [CrossRef]

58. Leroy, B.; Gillet, L.; Vanderplasschen, A.; Wattiez, R. Structural Proteomics of Herpesviruses. Viruses 2016, 8, 50. [CrossRef]

(C) 2019 by the authors. Licensee MDPI, Basel, Switzerland. This article is an open access article distributed under the terms and conditions of the Creative Commons Attribution (CC BY) license (http://creativecommons.org/licenses/by/4.0/). 